\title{
Logistic regression analysis of risk factors for postoperative recurrence of spinal tumors and analysis of prognostic factors
}

\author{
SHANYONG ZHANG, LILI YANG, CHUANGANG PENG and MINFEI WU \\ Department of Orthopedics, The Second Hospital of Jilin University, Changchun, Jilin 130041, P.R. China
}

Received June 28, 2017; Accepted November 13, 2017

DOI: $10.3892 / \mathrm{ol} .2017 .7509$

\begin{abstract}
The aim of the present study was to investigate the risk factors for postoperative recurrence of spinal tumors by logistic regression analysis and analysis of prognostic factors. In total, 77 male and 48 female patients with spinal tumor were selected in our hospital from January, 2010 to December, 2015 and divided into the benign $(n=76)$ and malignant groups $(n=49)$. All the patients underwent microsurgical resection of spinal tumors and were reviewed regularly 3 months after operation. The McCormick grading system was used to evaluate the postoperative spinal cord function. Data were subjected to statistical analysis. Of the 125 cases, 63 cases showed improvement after operation, 50 cases were stable, and deterioration was found in 12 cases. The improvement rate of patients with cervical spine tumor, which reached $56.3 \%$, was the highest. Fifty-two cases of sensory disturbance, 34 cases of pain, 30 cases of inability to exercise, 26 cases of ataxia, and 12 cases of sphincter disorders were found after operation. Seventy-two cases (57.6\%) underwent total resection, 18 cases (14.4\%) received subtotal resection, 23 cases (18.4\%) received partial resection, and 12 cases $(9.6 \%)$ were only treated with biopsy/decompression. Postoperative recurrence was found in 57 cases $(45.6 \%)$. The mean recurrence time of patients in the malignant group was $27.49 \pm 6.09$ months, and the mean recurrence time of patients in the benign group was $40.62 \pm 4.34$ The results were significantly different $(\mathrm{P}<0.001)$. Recurrence was found in 18 cases of the benign group and 39 cases of the malignant group, and results were significantly different $(\mathrm{P}<0.001)$. Tumor recurrence was shorter in patients with a higher McCormick grade $(\mathrm{P}<0.001)$. Recurrence was found in 13 patients with resection and all the patients with partial resection or biopsy/decompression. The results were significantly different $(\mathrm{P}<0.001)$. Logistic regression analysis of total resection-related factors showed that total resection should
\end{abstract}

Correspondence to: Dr Minfei Wu, Department of Orthopedics, The Second Hospital of Jilin University, 218 Ziqiang Street, Changchun, Jilin 130041, P.R. China

E-mail: wumingfei1200@163.com

Key words: spinal tumor, recurrence, risk factors, logistic regression analysis be the preferred treatment for patients with benign tumors, thoracic and lumbosacral tumors, and lower McCormick grade, as well as patients without syringomyelia and intramedullary tumors. Logistic regression analysis of recurrence-related factors revealed that the recurrence rate was relatively higher in patients with malignant, cervical, thoracic and lumbosacral, intramedullary tumors, and higher McCormick grade and patient received partial resection or biopsy. Tumor property, tumor location, McCormick grade, tumor resection, and intramedullary tumors are risk factors for the recurrence of spinal tumors. Clinical assessment of these risk factors may be helpful in selecting appropriate treatment strategies.

\section{Introduction}

Spinal tumors are relatively rare in clinical practice (1-3). However, due to the complex anatomical structure of the spine and the spinal cord, as well as large vessels and vital organs around the spine, the risk of surgical resection is relatively high. Therefore, subtotal resection has become the major treatment options for spinal tumors. However, the recurrence rate of subtotal resection is high, which in turn reduces the treatment efficacy (4-7).

Over the past 20 years, with the development of microsurgical technology, materials science, ergonomics and computer technology, understanding of surgeons in regard to spinal tumors has improved, and the treatment efficacy of spinal tumors has also significantly increased $(8,9)$. Through retrospective studies of surgical approach, resection methods, intraoperative bleeding control and spinal stability reconstruction, the resection rate was found to be significantly increased. By contrast, the complication, mortality and local recurrence rates were significantly reduced (8-12).

The risk factors of recurrent spinal tumors and the corresponding clinical treatment strategies involved have yet to be reported. Therefore, the aim of the study was to investigate the correlations between these risk factors.

\section{Materials and methods}

Subjects. Inclusion criteriafor the study were: Patients received spinal cancer surgery more than 12 months before, quality of life scale score was $\geq 70$ points, patients received surgery or biopsy, patients and their families voluntarily participated in the study and signed informed consent, and patients with 
normal function of major organs who showed no chemotherapy contraindications. Exclusion criteria for the study were: Patients combined with severe brain, heart, liver, renal and blood system diseases, as well as pregnant and lactating women.

In total, 125 patients with spine tumors including 77 males and 48 females were selected from January, 2010 to December, 2015. The ages ranged from 14 to 75 years with a median age of 41 years. There were 32 cases of cervical spine tumors, 5 cases of cervical thoracic spinal tumors, 31 cases of thoracic spine tumors, 34 cases of lumbosacral spine tumors, and 23 cases of thoracolumbar sacral spine tumors. Ependymoma was found in 42 cases, astrocytoma in 30 cases, hemangioblastoma in 14 cases, cavernous hemangioma in 7 cases, hamartoma in 6 cases, lipoma in 6 cases, dermoid cyst in 5 cases, metastatic tumor in 4 cases, ganglion glioma in 4 cases, neuroma in 4 cases, and meningioma in 3 cases. None of the patients had any history of radiation therapy.

Surgical methods. All 125 patients with spinal tumor were treated by microsurgical resection of spinal tumor. Limb movement, body surface sensation and anal sphincter function were monitored by the intraoperative application of neural electrophysiological equipment. The patients only underwent treatment with a high dose of methylprednisolone combined with neurotrophic drug therapy. Patients with limb movement disorders were treated with acupuncture and rehabilitation training 1 week after operation. All the patients were reviewed by nuclear magnetic resonance imaging to check possible recurrence. The McCormick grading system was used to evaluate the postoperative spinal cord function. Patients with increased McCormick (1 grade or more) were treated as patients with improvement, while patients with decreased McCormick (1 grade or more) were treated as patients with deterioration.

Statistical analysis. Data were processed by SPSS 20.0 statistical software (IBM, Armonk, NY, USA). Measurement data were expressed as mean \pm standard deviation, t-test was performed for comparisons between groups, and data that did not fit the normal distribution were processed using $U$ test. Countable data were expressed as $\%$, comparisons between groups were performed using $\chi^{2}$, and the on-recurrence survival rate was calculated by Kaplan-Meier method. Multivariate analysis was performed by Logistic multiple regression analysis. $\mathrm{P}<0.05$ was considered to indicate a statistically significant difference.

\section{Results}

Treatment efficacy. Of the 77 male patients, the proportion of patients with thoracic and lumbosacral tumors was the largest, reaching $27.3 \%$ (21/77), followed by cervical, lumbosacral, thoracic and cervicothoracic. Of the 48 female patients, the proportion of patients with lumbosacral tumors was the largest, reaching $33.3 \%$ (16/48), followed by the thoracic, cervical, thoracolumbar sacral and cervicothoracic tumors (Table I). Sixty-three cases showed improvement after operation, 50 cases were stable, and deterioration was found in 12 cases. The improvement rate of patients with cervical spine tumor,
Table I. Distribution of sex and tumor location of 125 patients with spinal tumors [cases (\%)].

\begin{tabular}{lrcc}
\hline Tumor locations & $\mathrm{n}$ & Male & Female \\
\hline Cervical & 32 & $19(24.7)$ & $13(27.1)$ \\
Cervicothoracic & 5 & $3(3.9)$ & $2(4.2)$ \\
Thoracic & 31 & $16(20.8)$ & $15(31.3)$ \\
Lumbosacral & 34 & $18(23.4)$ & $16(33.3)$ \\
Thoracic and lumbosacral & 23 & $21(27.3)$ & $2(4.2)$ \\
Total & 125 & $77(100.0)$ & $48(100.0)$ \\
\end{tabular}

Comparison of tumor locations between sexes $\chi^{2}=11.03, \mathrm{P}=0.026$.

which reached $56.3 \%$, was the highest, followed by thoracic, lumbosacral, thoracic and lumbosacral and cervicothoracic tumors (Table II). Postoperative symptoms included: 52 cases of sensory disturbance, 34 cases of pain, 30 cases of inability to exercise, 26 cases of ataxia and 12 cases of sphincter disorders (Table III).

Correlation between tumor type and surgical resection. With microsurgical resection, there were 72 cases $(57.6 \%)$ of total resection, 18 cases $(14.4 \%)$ of subtotal resection, 23 cases $(18.4 \%)$ of partial resection and 12 cases $(9.6 \%)$ of biopsy/ decompression due to the existing of multiple lesions. Total resection rate of neuroma was $100.0 \%$ (4/4), followed by hematoblastoma $92.9 \%(13 / 14)$, cavernous hemangioma $85.7 \%(6 / 7)$, ependymoma $83.3 \%$ (35/42), ganglion glioma $75.0 \%(3 / 4)$, meningioma $66.7 \%(2 / 3)$, dermoid cysts $40.0 \%(2 / 5)$, metastatic tumor $25.0 \%(1 / 4)$, hamartoma $16.7 \%(1 / 6)$ and astrocytoma $16.7 \%(5 / 30)$ (Table IV).

Tumor recurrence. Of the 125 patients with spinal tumors, $57(45.6 \%)$ had tumor recurrence at different time points after surgery. The mean recurrence time of 49 patients with malignant tumor was $27.49 \pm 6.09$ months, while the recurrence time of 76 patients with benign tumor was $40.62 \pm 4.34$ months. Recurrence-free survival rate of patients with benign tumor was significantly higher than that of patients with malignant tumor $(\mathrm{P}<0.001)$. The recurrence-free survival time of patients with malignant tumor was significantly shorter than that of patients with benign tumor $(\mathrm{P}<0.001)$ (Figs. 1 and 2$)$. Thirty-six males and 21 females showed recurrence, and no significant difference was found between sexes $(\mathrm{P}=0.142)$. Recurrence was found in 18 cases of benign tumors $(23.7 \%)$ and 39 cases of malignant tumor $(79.6 \%)$, and the results were significantly different $(\mathrm{P}<0.001)$. Among the patients with recurrence, 17 cases had a McCormick grade of I or II $(21.8 \%), 30$ cases had a grade of III $(81.1 \%)$, and 10 cases had a grade of VI and V (100\%), and the results showed significant differences $(\mathrm{P}<0.001)$. Patients with higher McCormick grade showed a significantly higher recurrence rate $(\mathrm{P}<0.001)$ (Fig. 3). Recurrence was found in 13 cases of 72 patients who received total resection and all patients receiving partial resection and biopsy/decompression, significant difference was found between them $(\mathrm{P}<0.001)$. Recurrence was found in 3 cases $(42.9 \%)$ of patients below 25 years, 43 cases $(45.3 \%)$ 
Table II. Correlation between tumor locations and treatment outcomes in 125 patients [cases (\%)].

\begin{tabular}{lrrrr}
\hline Tumor locations & $\mathrm{n}$ & Improvement & Stable & Deterioration \\
\hline Cervical & 32 & $18(56.3)$ & $11(34.3)$ & $3(9.4)$ \\
Cervicothoracic & 5 & $2(40.0)$ & $2(40.0)$ & $1(20.0)$ \\
Thoracic & 31 & $16(51.6)$ & $13(41.9)$ & $2(6.5)$ \\
Lumbosacral & 34 & $16(47.1)$ & $14(41.2)$ & $4(11.7)$ \\
Thoracic and lumbosacral & 23 & $11(47.8)$ & $10(43.5)$ & $2(8.7)$ \\
Total & 125 & $63(50.4)$ & $50(40.0)$ & $12(9.6)$ \\
\hline
\end{tabular}

Table III. Correlation between tumor locations and postoperative complications in 125 patients [cases $(\%)$ ].

\begin{tabular}{lrrrrrr}
\hline Tumor locations & $\mathrm{n}$ & $\begin{array}{c}\text { Sensory } \\
\text { disturbance }\end{array}$ & Pain & $\begin{array}{c}\text { Inability to } \\
\text { exercise }\end{array}$ & Ataxia & $\begin{array}{c}\text { Aphincter } \\
\text { disorders }\end{array}$ \\
\hline Cervical & 32 & $13(40.6)$ & $7(21.9)$ & $7(21.9)$ & $6(18.8)$ & $2(6.3)$ \\
Cervicothoracic & 5 & $2(40.0)$ & $1(20.0)$ & $2(40.0)$ & $1(20.0)$ & $0(0.0)$ \\
Thoracic & 31 & $12(38.7)$ & $8(25.8)$ & $7(22.6)$ & $6(19.4)$ & $4(12.9)$ \\
Lumbosacral & 34 & $13(38.2)$ & $10(29.4)$ & $8(23.5)$ & $8(23.5)$ & $3(8.8)$ \\
Thoracic and lumbosacral & 23 & $12(52.2)$ & $8(34.8)$ & $6(26.1)$ & $5(21.7)$ & $3(13.0)$ \\
Total & 125 & $52(41.6)$ & $34(27.2)$ & $30(24.0)$ & $26(20.8)$ & $12(9.6)$ \\
\hline
\end{tabular}

Table IV. Correlation between pathological tumor types and surgical resection [cases (\%)].

\begin{tabular}{lccccr}
\hline Pathological types & Total resection & Subtotal resection & Partial resection & Biopsy/decompression & Total \\
\hline Ependymoma & $35(83.3)$ & $3(7.1)$ & $2(4.8)$ & $2(4.8)$ & 42 \\
Astrocytoma & $5(16.7)$ & $8(26.7)$ & $14(46.7)$ & $3(10.0)$ & 30 \\
Hemangioblastoma & $13(92.9)$ & $1(7.1)$ & $0(0.0)$ & $0(0.0)$ & 14 \\
Cavernous hemangioma & $6(85.7)$ & $1(14.3)$ & $0(0.0)$ & $0(0.0)$ & 7 \\
Hamartoma & $1(16.7)$ & $1(16.7)$ & $2(33.3)$ & $2(33.3)$ & 6 \\
Lipoma & $0(0.0)$ & $0(0.0)$ & $3(50.0)$ & $3(50.0)$ & 6 \\
Dermoid cysts & $2(40.0)$ & $1(20.0)$ & $1(20.0)$ & $1(20.0)$ & 5 \\
Metastatic tumor & $1(25.0)$ & $1(25.0)$ & $1(25.0)$ & $1(25.0)$ & 4 \\
Ganglion glioma & $3(75.0)$ & $1(25.0)$ & $0(0.0)$ & $0(0.0)$ & 4 \\
Neuroma & $4(100.0)$ & $0(0.0)$ & $0(0.0)$ & $0(0.0)$ & 4 \\
Meningioma & $2(66.7)$ & $1(33.3)$ & $0(0.0)$ & $0(0.0)$ & 3 \\
Total & $72(57.6)$ & $18(14.4)$ & $23(18.4)$ & $12(9.6)$ & 125 \\
\hline
\end{tabular}

of patients between 25 and 60 years, and 11 cases $(47.8 \%)$ of patients above 60 years, with the results showing no significant differences were. No significant difference in recurrence time was found between different age groups (Fig. 4). The comparisons of recurrence rate between patients with different pathological tumor types are listed in Table V.

Logistic regression analysis of total surgical resection-related factors. Logistic regression analysis of total surgical resectionrelated factors was carried out. Significant differences in degree of resection were found between patients with different tumor properties (Wald Chi-square value $=32.429$, potence ratio: $10.386, \mathrm{P}<0.05)$, indicating that the total resection was preferred for patients with benign tumors. Significant differences in the degree of resection were found between patients with different tumor positions (Wald Chi-square value=9.453, potence ratio: $0.550, \mathrm{P}<0.05)$, indicating that the total resection was preferred for patients with thoracic and lumbosacral tumors. Significant differences in the degree of resection were also found between patients with different McCormick grades (Wald Chi-square value $=30.571$, potence ratio: 7.442, $\mathrm{P}<0.05$ ), indicating that the total resection was preferred for patients with lower McCormick grades. Significant differences in the degree of resection were aslo found between patients with or 


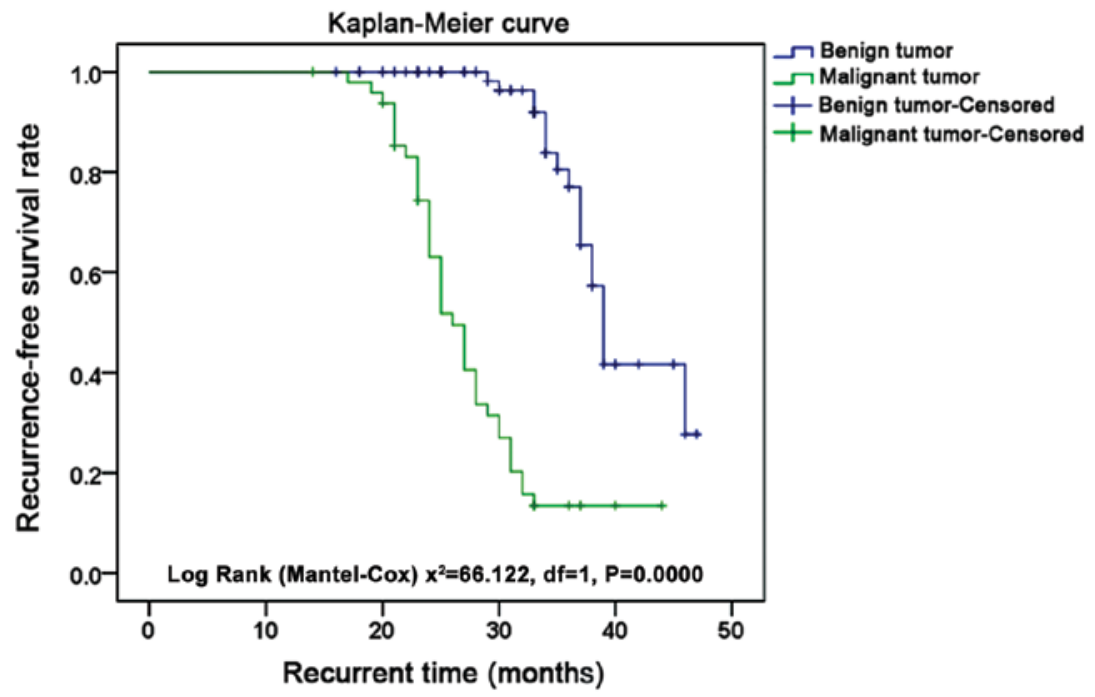

Figure 1. The recurrence-free survival rate using the Kaplan-Meier curve of patients with benign and malignant tumors. Recurrence-free survival rate of patients with benign tumors was significantly higher than that of patients with malignant tumors $(\mathrm{P}<0.001)$.

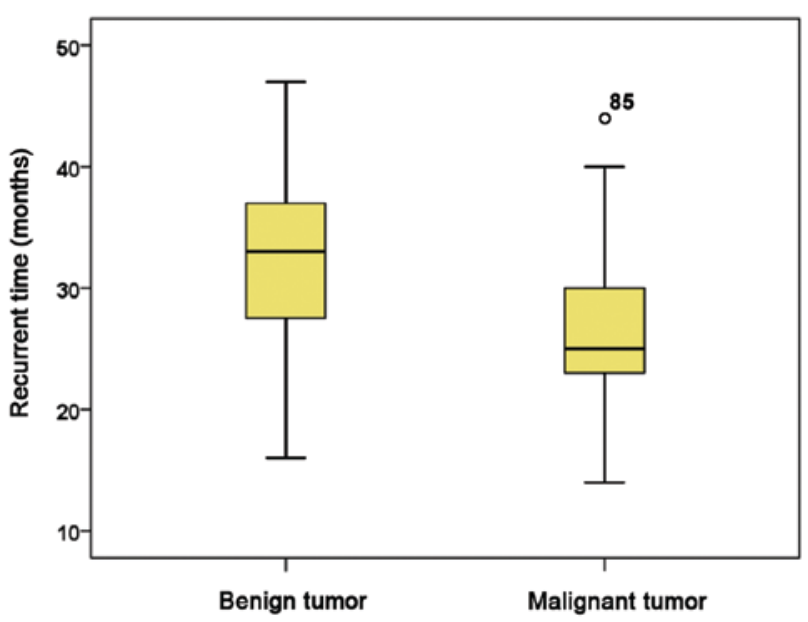

Figure 2. Comparison of recurrence time between patients with benign and malignant tumors. The recurrence time of patients with malignant tumor was significantly shorter than that of patients with benign tumors $(\mathrm{P}<0.001)$.

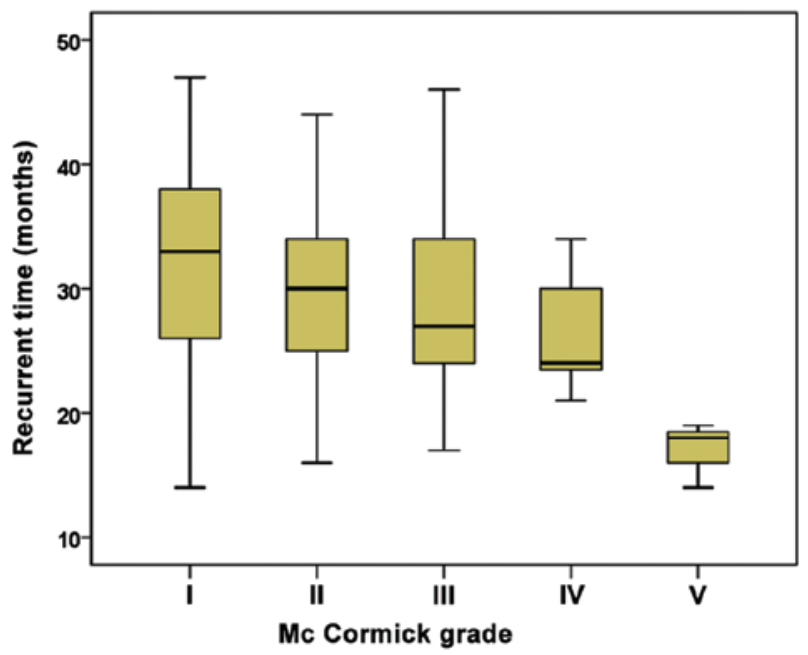

Figure 3. Comparison of recurrence time between patients with different McCormick grades. Patients with higher McCormick grade showed a significantly higher recurrence rate $(\mathrm{P}<0.001)$. without syringomyelia (Wald Chi-square value $=9.781$, potence ratio: $0.962, \mathrm{P}<0.05$ ), indicating the total resection is preferred for patients without syringomyelia. Significant differences in the degree of resection were also found between patients with or without intramedullary tumors (Wald Chi-square value $=11.199$, potence ratio: $1.167, \mathrm{P}<0.05$ ), indicating that total resection was preferred for patients without intramedullary tumors (Table VI).

Logistic regression analysis of risk factors of spinal tumor recurrence. Logistic regression analysis of risk factors of spinal tumor recurrence was carried out. Significant differences in the tumor recurrence rate were found between patients with different tumor properties (Wald Chi-square value $=32.283$, potence ratio: $12.567, \mathrm{P}<0.05)$, indicating that the tumor recurrence rate was higher in patients with malignant tumors than that of patients with malignant tumors. Significant differences in tumor recurrence rate were found between patients with different tumor positions (Wald Chi-square value $=9.307$, potence ratio: $0.665, \mathrm{P}<0.05$ ), indicating that tumor recurrence rate was higher in patients with cervical and thoracic and lumbosacral tumors than in patient with other tumor positions. Significant differences in the tumor recurrence rate were also found between patients with different McCormick grades (Wald Chi-square value $=30.425$, potence ratio: 9.005 , $\mathrm{P}<0.05$ ), suggesting that the tumor recurrence rate was higher in patients with higher McCormick grades than in patients with lower McCormick grades. Significant differences in the tumor recurrence rate were found between patients with or without total resection (Wald Chi-square value $=9.634$, potence ratio: $1.164, \mathrm{P}<0.05$ ), indicating that the recurrence rate was higher in patients with partial resection or biopsy/decompression than in patients with total resection. In addition, significant differences in the tumor recurrence rate were also found between patients with or without intramedullary tumors (Wald Chi-square value $=11.053$, potence ratio: $1.412, \mathrm{P}<0.05$ ), suggesting that the recurrence rate was higher in patients with intramedullary tumors than in patients without intramedullary tumors (Table VII). 
Table V. Comparisons of recurrence rate between patients with different pathological backgrounds $(n=125)$.

\begin{tabular}{|c|c|c|c|c|c|}
\hline Items & $\mathrm{n}$ & Recurrence & Non-recurrence & $\chi^{2}$ value & P-value \\
\hline Sex & & & & 0.113 & 0.142 \\
\hline Male & 77 & $36(46.8)$ & $41(53.2)$ & & \\
\hline Female & 48 & $21(43.8)$ & $27(56.3)$ & & \\
\hline Age (years) & & & & 0.069 & 0.241 \\
\hline$<25$ & 7 & $3(42.9)$ & $4(57.1)$ & & \\
\hline $25-60$ & 95 & $43(45.3)$ & $52(54.7)$ & & \\
\hline$>60$ & 23 & $11(47.8)$ & $12(52.2)$ & & \\
\hline Tumor properties & & & & 37.543 & 0.000 \\
\hline Benign & 76 & $18(23.7)$ & $58(76.3)$ & & \\
\hline Malignant & 49 & $39(79.6)$ & $10(20.4)$ & & \\
\hline Tumor positions & & & & 4.662 & 0.073 \\
\hline Cervical & 32 & $16(50.0)$ & $16(50.0)$ & & \\
\hline Cervicothoracic & 5 & $4(80.0)$ & $1(20.0)$ & & \\
\hline Thoracic & 31 & $13(41.9)$ & $18(58.1)$ & & \\
\hline Lumbosacral & 34 & $12(35.3)$ & $22(64.7)$ & & \\
\hline Thoracic and lumbosacral & 23 & $12(52.2)$ & $11(47.8)$ & & \\
\hline McCormick grades & & & & 48.531 & 0.000 \\
\hline I and II & 78 & $17(21.8)$ & $61(78.2)$ & & \\
\hline III & 37 & $30(81.1)$ & $7(18.9)$ & & \\
\hline IV and V & 10 & $10(100.0)$ & $0(0.0)$ & & \\
\hline Resection & & & & 63.924 & 0.000 \\
\hline Total resection & 72 & $13(18.1)$ & $59(81.9)$ & & \\
\hline Subtotal resection & 18 & $9(50.0)$ & $9(50.0)$ & & \\
\hline Partial resection & 23 & $23(100.0)$ & $0(0.0)$ & & \\
\hline Biopsy/decompression & 12 & $12(100.0)$ & $0(0.0)$ & & \\
\hline
\end{tabular}

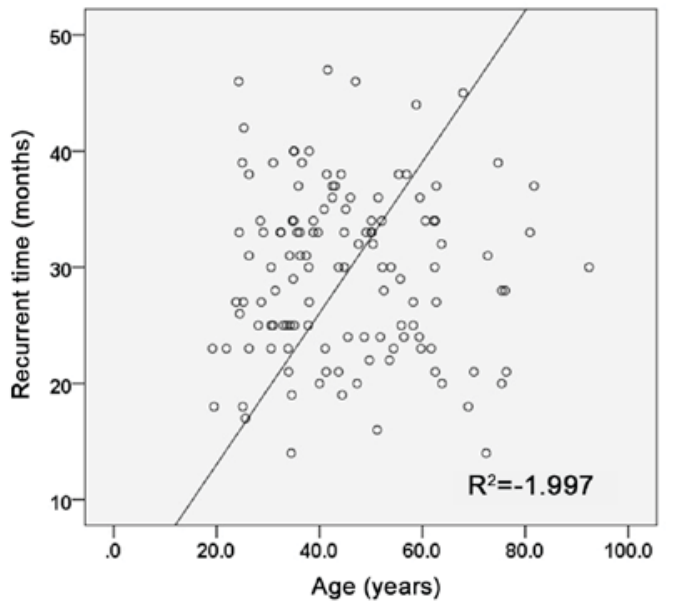

Figure 4. Comparison of recurrence time between patients of different age groups. No significant difference in recurrence time was found among the different age groups.

\section{Discussion}

The incidence rate of spinal tumors is approximately $6.6 \%$ to $8.8 \%(13)$, which is a low level. However, spinal tumors have many pathological types and also lack characteristic clinical manifestations at the early stage. Thus, the treatment of spinal tumors is usually delayed, which in turn affects prognosis $(14,15)$. In recent years, with the advancement of medical imaging technology, the early diagnosis of spinal tumors has become possible. Combined with advances in microsurgical techniques, robotic techniques and biomedical materials, the surgical treatment of spinal tumors has been significantly improved and the treatment efficacy significantly increased $(16,17)$. Therefore, how to further improve the efficacy of surgical treatment, improve the long-term control rate of cancer, design a reasonable treatment plan, and reduce surgical complications has become a hot research field.

The majority of primary spinal tumors are malignant tumors. However, the majority of surgical studies are usually focused on the treatment of benign tumors, which may be explained by the loss of surgical opportunities of malignant tumors and the radioactive treatment-dominated treatment strategy. Surgical treatment is the main treatment of spinal tumors, but the risk is high and the incidence of postoperative complication is also high. In addition, surgical operations may injure important blood vessels and nerves, resulting in spinal cord ischemia or injury and the postoperative recurrence of tumor (18). A retrospective study carried by Klekamp (19) 
Table VI. Logistic regression analysis of total surgical resection-related factors.

$95 \%$ confidence interval

\begin{tabular}{|c|c|c|c|c|c|c|c|c|}
\hline \multirow[b]{2}{*}{ Variable } & \multirow[b]{2}{*}{ Coefficient } & \multirow[b]{2}{*}{$\begin{array}{l}\text { Standard } \\
\text { deviation }\end{array}$} & \multirow{2}{*}{$\begin{array}{c}\text { Wald } \\
\text { Chi-square } \\
\text { value }\end{array}$} & \multirow{2}{*}{$\begin{array}{l}\text { Degree } \\
\text { of } \\
\text { freedom }\end{array}$} & \multirow[b]{2}{*}{ P-value } & \multirow[b]{2}{*}{$\begin{array}{l}\text { Potence } \\
\text { ratio }\end{array}$} & \multicolumn{2}{|c|}{ interval } \\
\hline & & & & & & & $\begin{array}{l}\text { Lower } \\
\text { limit }\end{array}$ & $\begin{array}{c}\text { Upper } \\
\text { limit }\end{array}$ \\
\hline Sex & 0.401 & 0.898 & 0.321 & 1 & 0.624 & 1.546 & 0.664 & 2.406 \\
\hline Age & 0.32 & 0.677 & 0.312 & 1 & 0.841 & 0.998 & 0.435 & 2.458 \\
\hline Tumor properties & 2.663 & 0.66 & 32.429 & 1 & 0.027 & 10.386 & 4.674 & 24.764 \\
\hline Tumor position & -0.275 & 0.348 & 9.453 & 1 & 0.009 & 0.550 & 0.456 & 0.711 \\
\hline McCormick grades & 2.33 & 0.613 & 30.571 & 1 & 0.007 & 7.442 & 3.672 & 16.184 \\
\hline With or without syringomyelia & 0.036 & 0.397 & 9.781 & 1 & 0.021 & 0.962 & 0.938 & 2.564 \\
\hline With or without intramedullary tumors & 1.167 & 0.58 & 11.199 & 1 & 0.011 & 1.167 & 0.707 & 2.184 \\
\hline
\end{tabular}

Table VII. Logistic regression analysis of recurrence-related factors.

\begin{tabular}{|c|c|c|c|c|c|c|c|c|}
\hline \multirow[b]{2}{*}{ Variable } & \multirow[b]{2}{*}{ Coefficient } & \multirow[b]{2}{*}{$\begin{array}{l}\text { Standard } \\
\text { deviation }\end{array}$} & \multirow{2}{*}{$\begin{array}{c}\text { Wald } \\
\chi^{2} \\
\text { value }\end{array}$} & \multirow{2}{*}{$\begin{array}{l}\text { Degree } \\
\text { of } \\
\text { freedom }\end{array}$} & \multirow[b]{2}{*}{ P-value } & \multirow[b]{2}{*}{$\begin{array}{l}\text { Potence } \\
\text { ratio }\end{array}$} & \multicolumn{2}{|c|}{$\begin{array}{c}95 \% \text { confidence } \\
\text { interval }\end{array}$} \\
\hline & & & & & & & $\begin{array}{l}\text { Lower } \\
\text { limit }\end{array}$ & $\begin{array}{l}\text { Upper } \\
\text { limit }\end{array}$ \\
\hline Sex & 0.269 & 0.683 & 0.175 & 1 & 0.467 & 1.871 & 0.746 & 2.923 \\
\hline Age & 0.188 & 0.462 & 0.166 & 1 & 0.684 & 1.207 & 0.488 & 2.987 \\
\hline Tumor properties & 2.531 & 0.445 & 32.283 & 1 & 0.000 & 12.567 & 5.249 & 30.088 \\
\hline Tumor position & -0.407 & 0.133 & 9.307 & 1 & 0.002 & 0.665 & 0.512 & 0.864 \\
\hline McCormick grades & 2.198 & 0.398 & 30.425 & 1 & 0.000 & 9.005 & 4.124 & 19.663 \\
\hline With or without total resection & -0.096 & 0.182 & 9.634 & 1 & 0.024 & 1.164 & 1.053 & 3.115 \\
\hline With or without intramedullary tumors & 1.035 & 0.365 & 11.053 & 1 & 0.014 & 1.412 & 0.794 & 2.654 \\
\hline
\end{tabular}

found that the total resection rate of spinal tumors has been significantly improved in the last 30 years. Approximately $61 \%$ of patients with spinal tumors had neurological dysfunction after surgery, of which $41.5 \%$ were reversible. The incidence of permanent neurological deficit is approximately $19.5 \%$, which is closely related to the experience of surgeons and the state of the preoperative nervous system. Further analysis revealed that patients with thoracic tumors, tumor bleeding, malignancy and recurrent tumors usually had a higher risk of permanent complications (19).

The cause of spinal tumor recurrence is complex $(20,21)$. Pathological grade of the tumor has a significant effect on the recurrence rate of tumors and the survival status of patients. Except for some of cases of astrocytomas, recurrence is common in all malignant spinal tumors. Therefore, radiation therapy is preferred for patients with malignant spinal tumors (21). For invasive spondyloma tumors, total tumor resection or subtotal resection can effectively reduce the tumor recurrence rate. Effects of the degree of tumor resection on the recurrence rate of ependymoma have been very clear. Some studies have reported no significant correlation between tumor resection and progression-free survival in patients with astrocytomas, which may be explained by the small sample size (22).
In this study, recurrence was found in 57 cases of spinal tumors (45.6\%) after surgery. The recurrence time was shorter in patients with malignant tumors, and the recurrence rate was also higher than that of benign tumors. Patients with higher McCormick grades showed shorter recurrence time. This can be explained by the factor that tumors with higher McCormick grades are usually malignant tumors with a high invasion ability, causing difficulties to total resection and subtotal resection. Logistic regression analysis of total resection showed that total resection should be the preferred treatment for patients with benign tumors, thoracic and lumbosacral tumors and lower McCormick grades, as well as patients without syringomyelia and intramedullary tumors. Logistic regression analysis of recurrence-related factors showed that the recurrence rate was higher in patients with malignant tumors, cervical and thoracic and lumbosacral tumors, higher McCormick grades and intramedullary tumors, and patients receiving partial resection or biopsy/decompression treatment.

In summary, tumor properties, tumor locations, McCormick grades, degrees of tumor resection and intramedullary tumors are risk factors for the postoperative recurrence of spinal tumors. Clinical assessment of these risk factors may be helpful in selecting appropriate treatment strategies. 


\section{References}

1. Hariri O, Takayanagi A, Miulli DE, Siddiqi J and Vrionis F: Minimally invasive surgical techniques for management of painful metastatic and primary spinal tumors. Cureus 9: e1114, 2017.

2. Dea N, Gokaslan Z, Choi D and Fisher C: Spine oncologyprimary spine tumors. Neurosurgery 80: S124-S130, 2017.

3. Mechtler LL and Nandigam K: Spinal cord tumors: New views and future directions. Neurol Clin 31: 241-268, 2013.

4. Kato S, Murakami H, Demura S, Yoshioka K, Kawahara N, Tomita K and Tsuchiya H: More than 10-year follow-up after total en bloc spondylectomy for spinal tumors. Ann Surg Oncol 21: 1330-1336, 2014.

5. Tokuhashi Y, Uei H, Oshima M and Ajiro Y: Scoring system for prediction of metastatic spine tumor prognosis. World J Orthop 5: 262-271, 2014.

6. Shi R, Wang PY, Li XY, Chen JX, Li Y, Zhang XZ, Zhang CG, Jiang T, Li WB, Ding W, et al: Exosomal levels of miRNA-21 from cerebrospinal fluids associated with poor prognosis and tumor recurrence of glioma patients. Oncotarget 6: 26971-26981, 2015.

7. Sun SQ, Cai C, Ravindra VM, Gamble P, Yarbrough CK, Dacey RG, Dowling JL, Zipfel GJ, Wright NM, Santiago P, et al: Simpson grade I-III resection of spinal atypical (World Health Organization Grade II) meningiomas is associated with symptom resolution and low recurrence. Neurosurgery 76: 739-746, 2015.

8. Karikari IO, Nimjee SM, Hodges TR, Cutrell E, Hughes BD, Powers CJ, Mehta AI, Hardin C, Bagley CA, Isaacs RE, et al Impact of tumor histology on resectability and neurological outcome in primary intramedullary spinal cord tumors: A singlecenter experience with 102 patients. Neurosurgery 76 (Suppl 1): S4-S13, 2015.

9. Varga PP, Szövérfi Z, Fisher CG, Boriani S, Gokaslan ZL, Dekutoski MB, Chou D, Quraishi NA, Reynolds JJ, Luzzati A, et al: Surgical treatment of sacral chordoma: Prognostic variables for local recurrence and overall survival. Eur Spine J 24: 1092-1101, 2015.

10. Tang C, Hess K, Bishop AJ, Pan HY, Christensen EN, Yang JN, Tannir N, Amini B, Tatsui C, Rhines L, et al: Creation of a prognostic index for spine metastasis to stratify survival in patients treated with spinal stereotactic radiosurgery: Secondary analysis of mature prospective trials. Int J Radiat Oncol Biol Phys 93: $118-125,2015$.

11. Bishop AJ, Tao R, Rebueno NC, Christensen EN, Allen PK, Wang XA, Amini B, Tannir NM, Tatsui CE, Rhines LD, et al: Outcomes for spine stereotactic body radiation therapy and an analysis of predictors of local recurrence. Int J Radiat Oncol Biol Phys 92: 1016-1026, 2015.

12. Matamalas A, Gargallo A, Porcel JA, García de Frutos A and Pellisé F: Cervical spine epithelioid hemangioendothelioma: Case report. Eur Rev Med Pharmacol Sci 18 (Suppl 1): 72-75, 2014.
13. Vera-Bolanos E, Aldape K, Yuan Y, Wu J, Wani K, Necesito-Reyes MJ, Colman H, Dhall G, Lieberman FS, Metellus P, et al; CERN Foundation: Clinical course and progression-free survival of adult intracranial and spinal ependymoma patients. Neuro Oncol 17: 440-447, 2015.

14. Goldschlager T, Dea N, Boyd M, Reynolds J, Patel S, Rhines LD, Mendel E, Pacheco M, Ramos E, Mattei TA, et al: Giant cell tumors of the spine: Has denosumab changed the treatment paradigm? J Neurosurg Spine 22: 526-533, 2015.

15. Jahangiri A, Chin AT, Wagner JR, Kunwar S, Ames C, Chou D, Barani I, Parsa AT, McDermott MW, Benet A, et al: Factors predicting recurrence after resection of clival chordoma using variable surgical approaches and radiation modalities. Neurosurgery 76: 179-186, 2015.

16. Xu W, Li X, Huang W, Wang Y, Han S, Chen S, Xu L, Yang X, Liu T and Xiao J: Factors affecting prognosis of patients with giant cell tumors of the mobile spine: Retrospective analysis of 102 patients in a single center. Ann Surg Oncol 20: 804-810, 2013.

17. Huang L, Chen K, Ye JC, Tang Y, Yang R, Wang P and Shen HY: Modified total en bloc spondylectomy for thoracolumbar spinal tumors via a single posterior approach. Eur Spine J 22: 556-564, 2013.

18. Ahmed R, Menezes AH, Awe OO and Torner JC: Long-term disease and neurological outcomes in patients with pediatric intramedullary spinal cord tumors. J Neurosurg Pediatr 13: 600-612, 2014

19. Klekamp J: Treatment of intramedullary tumors: Analysis of surgical morbidity and long-term results. J Neurosurg Spine 19: 12-26, 2013.

20. Prejbeanu R1, Vlad Daliborca C, Dumitrascu V, Vermesan D, Mioc M, Abbinante A andCagiano R: Application of acrylic spacers for long bone defects after tumoral resections. Eur Rev Med Pharmacol Sci 17: 2366-2371, 2013.

21. Oh MC, Kim JM, Kaur G, Safaee M, Sun MZ, Singh A, Aranda D, Molinaro AM and Parsa AT: Prognosis by tumor location in adults with spinal ependymomas. J Neurosurg Spine 18: 226-235, 2013.

22. Nair S, Gobin YP, Leng LZ, Marcus JD, Bilsky M, Laufer I and Patsalides A: Preoperative embolization of hypervascular thoracic, lumbar, and sacral spinal column tumors: Technique and outcomes from a single center. Interv Neuroradiol 19: 377-385, 2013.

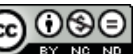

This work is licensed under a Creative Commons Attribution-NonCommercial-NoDerivatives 4.0 International (CC BY-NC-ND 4.0) License. 